\title{
EL SENTIDO INTERPRETATIVO DE LA PÉRDIDA DEL \\ BIEN EN LA OBLIGACIÓN PROVENIENTE DE DELITO O
}

\section{FALTA}

Michael Espinoza Coila *

\section{INFORMACIÓN DEL ARTÍCULO}

Art. Recibido: $12 / 08 / 2020$

Art. Aceptado: $12 / 08 / 2020$

Art. Publicado: $16 / 08 / 2020$ 


\title{
RESUMEN:
}

El presente artículo original breve, da conocer resultados preliminares de un estudio realizado en el año 2014 sobre la pérdida del bien en obligación proveniente de delito o falta y la restitución del bien regulada por el ordenamiento jurídico peruano, por consiguiente tiene el objetivo de establecer el sentido interpretativo del artículo $1140^{\circ}$ del Código Civil de Perú estableciéndose que el deudor (autor del delito o falta) tiene la obligación de pagar el valor del bien cierto, surgido por la comisión del delito o falta al acreedor (tercero adquirente de buena fe), por la imposibilidad jurídica de entregar un bien que fue restituido a su legitimo titular. Este supuesto no se aplica cuando el deudor (delincuente) ha constituido en mora al acreedor (tercero adquirente de buena fe).

Para llegar a este resultado, se acudió a los saberes del derecho de obligaciones y el derecho penal, que nos permitieron contextualizar el problema interpretativo.

En la investigación se empleo el método jurídico (dogmático jurídico), técnicas de interpretación jurídica y fichas textuales de revisión bibliográfica.

Palabras Claves: Perdida del bien, restitución del bien, delito, falta, repetición.

\section{LOSS OF PROPERTY IN CRIME FROM LIABILITY OR FAILURE}

\begin{abstract}
:
This original article brief, gives release preliminary results of a study conducted in the year 2014 on the loss of the good obligation from crime or misdemeanor and the restitution of property governed by Peruvian law, therefore it aims to establish the interpretive meaning of Article 1140 of the Civil Code of Peru established that the debtor (author of the crime or offense) is required to pay the value of a good, arising from the commission of the offense or lack the creditor (third party purchaser in good faith), by the legal impossibility to deliver a well that was returned to its rightful owner. This course does not apply when the debtor (the offender) has been in arrears to creditor (third party purchaser in good faith).

To reach this result, he came to the knowledge of contract law and criminal law, which allowed us to contextualize the interpretive problem.

The investigation employment legal method (legal dogmatic), techniques of legal interpretation and textual records of literature review.
\end{abstract}

Keywords: Loss of fine, restitution of property, felony, misdemeanor, repetition. 


\section{Introducción:}

La presente investigación tiene por origen los artículos $1140^{\circ}$ del Código Civil y $94^{\circ}$ del Código Penal, referidos a la pérdida del bien en obligación proveniente de delito o falta, y la restitución del bien, al cual en nuestro país, se le atribuyen varios sentidos a los mencionados artículos, algunos en favor del tercero adquirente de buena fe, y otras que decantan por una cuestión ética que defiende al titular legitimo del bien.

En esta oportunidad, respondemos al siguiente enunciado del problema: ¿Cuál es el sentido interpretativo de las disposiciones de los artículos $1140^{\circ}$ del Código Civil y $94^{\circ}$ del Código penal peruano?; en cuanto al objetivo de la investigación fue establecer un sentido interpretativo (variable dependiente) de los artículos $1140^{\circ}$ del Código Civil y $94^{\circ}$ del Código penal peruano (variable independiente); tratándose de un trabajo doctrinal meramente discursivo, no es necesario la hipótesis de investigación,

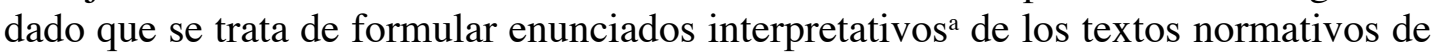
los artículos antes señalados, cuyas normas me permitieron arribar a una conclusión mas o menos asequibles a la miente pragmática de los agentes jurídicos, por cuanto no pretendo exponer un trabajo ubérrimo y complejo, más bien, algo sencillo y breve.

La razón principal que justifica la investigación, es la necesidad dar una adecuada interpretación al articulo $1140^{\circ}$ del Código Civil peruano.

La importancia del tema radica en ofrecer una solución dogmática a los agentes jurídicos dedicados a los negocios jurídicos que tiene por objeto la obligación de dar un bien cierto derivado de la comisión de delitos y faltas contra el patrimonio

La investigación es de tipo doctrinal (documental), aplicó el método jurídico (dogmático); el proceso investigación tuvo las siguientes etapas:(a) planteamiento del problema, (b) plan de acercamiento a la solución, (c) información metódica, (d) construcción de una solución y (e) formulación de soluciones; la actividad discursiva uso la técnica de la interpretación jurídica (literal, y sistemática), con instrumentos de fichaje textual para la revisión del material bibliográfico; y tuvo por población y objeto de estudio los artículos $1140^{\circ}$ del Código Civil y $94^{\circ}$ del Código Penal, referidos a la imposibilidad jurídica de entregar un bien que fue restituido a su legitimo titular, y la restitución del bien (unidad de estudio).

III. Estudio: El estudio se realizo en el semestre 2014-II, como parte de un trabajo encargado en el Curso de Derecho de Obligaciones en la Escuela Profesional de Derecho de la Universidad Nacional del Altiplano de Puno, fue menester su indagación por cuanto, la doctrina civil y penal no es uniforme y poco se habla del asunto, por ello nos preocupamos en evidenciar que es posible una conciliación de criterios entre el derecho civil y el penal; mediante el estudio dogmático del mismo avizoramos que los sujetos son el autor del delito en calidad de deudor, el tercero adquirente con el rol de acreedor, y el titular del bien, como un tercero más en la relación sustantiva, y que es posible una solución interpretativa entre los cuerpos legales de cada saber jurídico,

a Mayor información sobre los enunciados interpretativos y la interpretación jurídica en: GUASTINI, Riccardo (1 999). Estudios sobre la interpretación jurídica. Traducción de Marina Gascón y Miguel Carbonell. México. Instituto de Investigaciones Jurídicas. 


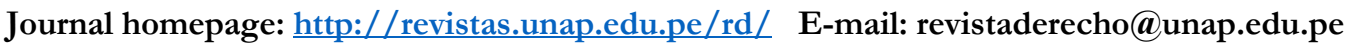

consistente en atribuir una responsabilidad jurídica conforme a la posición jurídica que ostentan en la relación obligacional, este paliativo permitirá que los operadores jurídicos tomen las decisiones más racionales en las sedes judiciales de nuestro país.

\section{Discusión:}

Los delitos o faltas pueden producir un perjuicio susceptible de apreciación pecuniaria, el llamado daño privado indemnizable, en el patrimonio, en la persona, o en los derechos o facultades de un tercero, con lo que se configura una obligación civil al cual el Estado establece mecanismos para hacerlas efectivas (ZAFFARONI, 1983 ; FONTAN, 1998 y MUÑOZ, 2002). Perteneciente a esta cuestión, la reparación civil nos permite: (a) hacernos pago en especie - la restitución del mismo bien- o (b) la indemnización pecuniaria - sobre el valor del bien cierto (Art. $93^{\circ}$ C.P.),

La restitución del bien mueble o inmueble al que se refiere el artículo $94^{\circ}$ del Código Penal peruano, es una institución que consiste en el restablecimiento del estado anterior del bien afectado por la comisión de un delito o falta, esto es, la devolución del bien que se halle en el señorío o posesión del delincuente, infractor y tercero ${ }^{b}$. (PEÑA, 1986; VILLAVICENCIO, 2001 y HURTADO, 2011).

Al tercero se le reconoce el derecho de repetición para reclamar el valor contra quien corresponda y el pago frutos y mejoras (Art. $917^{\circ}$ y $892^{\circ}$ C.C.), siempre que este haya adquirido de buena fe y a título oneroso sin saber el origen delictivo (Art. 2014 ${ }^{\circ}$ C.C.) (VILLAVICENCIO, 2001 y PEÑA CABRERA, 2011).

La restitución goza de un grado de preferencia frente a la indemnización (SOLER, 1992), empero, resulta conveniente el pago de una cantidad de dinero en compensación por el daño y los perjuicios ocasionados con el delito a la víctima, cuando el restablecimiento al estado anterior puede presentar dificultades por bien dañado, usado, fungible y personalismo (HURTADO, 2011 y PEÑA CABRERA, 2011).

Atinente al artículo $1140^{\circ}$ del Código Civil peruano ${ }^{\mathrm{c}}$, este contempla un principio ético al enunciar que cuando la deuda (obligación) de un bien cierto procediere de delito o falta no se exime el deudor de pagar su valor, aunque el bien se hubiese perdido sin su culpa (TORRES, 2014 y OSTERLING, 1988). Y como vimos lineas arriba, el artículo $94^{\circ}$ del Código Penal peruano, el titular de un bien tiene derecho a recuperar el bien ${ }^{\mathrm{d}}$, porque el ordenamiento jurídico no ampara la propiedad de origen delictivo por una motivación ética, en consecuencia, los terceros adquirentes o sub adquierentes a titulo oneroso y con buena fe, pueden ser despojados de su derecho de propiedad, lo cual no implica la privación del derecho de repetición, cobro de frutos y mejoras.

\footnotetext{
${ }^{b}$ El profesor Hurtado, indica: cuando el bien objeto del delito se encuentre en poder de terceros ajenos a su realización u origen, el art. 94 del Código Penal (agregado), prevé que éstos pueden demandar una compensación de su valor a quienes se los suministraron o transfirieron (Cf. HURTADO, 2 011:437).

c Artículo $1140^{\circ}$ C.C..- El deudor no queda eximido de pagar el valor del bien cierto, aunque éste se haya perdido sin culpa, cuando la obligación proviene de delito o falta. Esta regla no se aplica si el acreedor ha sido constituido en mora.

${ }^{\mathrm{d}}$ La reparación civil no sólo comprende la indemnización de los daños y perjuicios sino la restitución del bien. Estado Peruano y FONCODES contra Luis Alberto Muñoz Adrianzen (2002) Sala Penal. R. N. Nro. 3204-2001. Piura.
} 
V.gr. Un ladrón que sufrió la pena privativa de la libertad, tiene la obligación legal de restituir el bien a su legitimo titular y pagar el valor del bien cierto al tercero afectado.

Figura $N^{\circ} 01$

\begin{tabular}{|c|c|c|c|}
\hline Deudor & & Acreedor & Tercero \\
\hline Delincuente & $<--$ & $\begin{array}{c}\text { Tercero adquirente con } \\
\text { título oneroso y buena } \\
\text { fe. }\end{array}$ & $\begin{array}{l}\text { Titular del bien } \\
\text { legitimo. }\end{array}$ \\
\hline $\begin{array}{l}\text { Obligado a restituir el } \\
\text { bien a su titular, y } \\
\text { pagar el valor al tercero } \\
\text { adquirente. }\end{array}$ & & $\begin{array}{l}\text { El bien cierto es } \\
\text { pagado en su valor } \\
\text { (Art. } 1140^{\circ} \text { C.C.). }\end{array}$ & $\begin{array}{l}\text { El bien cierto es } \\
\text { restituido (Art. } 94^{\circ} \\
\text { C.P.). }\end{array}$ \\
\hline
\end{tabular}

Fuente: Elaboración propia.

Ahora podemos colegir que la perdida del bien por la restitución del bien derivado de delito o falta, no extingue la obligación del deudor (delincuente) y el acreedor (tercero adquirente de buena fe), de pagar el valor del bien cierto, en efecto, el pago será pecuniario y no con la entrega del mismo bien, porque el ordenamiento jurídico no fomenta la delincuencia, tampoco se aplica el inciso 5 del artículo $1138^{\circ}$ del mencionado código ${ }^{\mathrm{e}}$ (OSTERLING, 2011).

En ese orden de ideas, el profesor Torres señala que los actos jurídicos de transferencia de la propiedad $\mathrm{u}$ otros derechos reales sobre bienes adquiridos delictivamente adolecen de nulidad absoluta, puesto que nadie se puede comprometer a prestar bienes de origen delictivo (objeto ilícito) (2014).

En síntesis, el sentido normativo del artículo $1140^{\circ}$ del Código Civil, es que el deudor (autor del delito o falta) tiene la obligación de pagar el valor del bien cierto, surgida por la comisión del delito o falta, por la imposibilidad jurídica de entregar un bien que fue restituido a su legitimo titular. Ahora bien, la norma del primer párrafo del artículo $1140^{\circ}$ del Código Civil, no se aplica cuando el deudor (delincuente) ha constituido en mora al acreedor (tercero adquirente de buena fe), es decir cuando el acreedor (tercero adquirente de buena fe) se niega a aceptar la prestación ofrecida o no cumple con practicar los actos necesarios para que se pueda ejecutar la obligación (Art. $1338^{\circ}$ C.C. $)^{f}$ (TORRES, 2014 y BARCHI, 2004).

V.gr. El acreedor (tercero adquirente de buena fe) no cumple con pagar S/. 10 000.00 que ofreció al deudor (delincuente) por la compraventa de un terreno.

e Artículo $1138^{\circ}$ C.C..- En las obligaciones de dar bienes ciertos se observan, hasta su entrega, las reglas siguientes: (...) 5.- Si el bien se pierde sin culpa de las partes, la obligación del deudor queda resuelta, con pérdida del derecho a la contraprestación, si la hubiere. En este caso, corresponden al deudor los derechos y acciones que hubiesen quedado relativos al bien.

${ }^{\mathrm{f}}$ Artículo $1338^{\circ}$ C.C.- El acreedor incurre en mora cuando sin motivo legítimo se niega a aceptar la prestación ofrecida o no cumple con practicar los actos necesarios para que se pueda ejecutar la obligación. 
IV. Conclusiones: El sentido normativo del artículo $1140^{\circ}$ del Código Civil, es que el deudor (autor del delito o falta) tiene la obligación de pagar el valor del bien cierto, surgida por la comisión del delito o falta al acreedor (tercero adquirente de buena fe), por la imposibilidad jurídica de entregar un bien que fue restituido a su legitimo titular. Este supuesto no se aplica cuando el deudor (delincuente) ha constituido en mora al acreedor (tercero adquirente de buena fe).

\section{Referencias bibliográficas:}

BARCHI VELAOCHAGA, L. (2004). Pérdida del bien en obligación proveniente de delito o falta. En Gaceta Jurídica. Código Civil Comentado: Derecho de las obligaciones. Gaceta Jurídica.

Decreto Legislativo N 295 “Código Civil”. PRESIDENCIA DEL CONSEJO DE MINISTROS (1984).

Decreto Legislativo N 635 “Código Penal”. PRESIDENCIA DEL CONSEJO DE MINISTROS (1991).

FONTAN BALESTRA, C. (1998). Derecho penal: Introducción y parte general. Abeledo Perrot.

GUASTINI, R. (1999). Estudios sobre la interpretación jurídica. Traducción de Marina Gascón y Miguel Carbonell. Instituto de Investigaciones Jurídicas.

HURTADO POZO, J. \& PRADO SALDARRIAGA, V. (2 011). Manual de derecho penal: parte general. T.II. (4º ed.). IDEMSA.

MUÑOZ CONDE, F. (2 002). Derecho penal: parte general (5 ed.). Tirant lo bllanch. OSTERLING PARODI, F. \& CASTILLO FREYRE, M. (2 011). Compendio de derecho de las obligaciones. Palestra editores.

OSTERLING PARODI, F. (1 988). Las obligaciones. $\left(2^{\circ}\right.$ ed.). Fondo Ed. PUCP.

PEÑA CABRERA FREYRE, A. R. (2011). Derecho penal: parte general. T.II. $\left(3^{\circ}\right.$ ed.). IDEMSA.

PEÑA CABRERA, R. (1986). Tratado de derecho penal: parte general. V.I. (3 ed.). ED. SAGITARIO.

Sala Penal. R. N. Nro. 3204-2001 -Piura (2002)

SOLER, S. (1992). Derecho penal argentino II (4 ${ }^{\circ}$ ed). TEA.

TORRES VÁSQUEZ, A. (2 014).Teoría General de las Obligaciones. Pacifico Editores S.A.C.

VILLAVICENCIO TERREROS, F. (2001). Código penal comentado (3ed.). Grijley.

ZAFFARONI, E.R. (1983). Tratado de derecho penal. Tomo V. EDIAR. 